\title{
EVAPORATIVE COOLING TECHNOLOGY EFFICIENCY COMPARED TO TRADITIONAL COOLING SYSTEM - CASE STUDY
}

\author{
Viktors Afonicevs, Uldis Strauts, Nikolajs Bogdanovs, Arturs Lesinskis \\ Riga Technical University, Latvia \\ viktorsafonicevs@inbox.lv, uldis.strauts@gmail.com,nikolajsbms@gmail.com, \\ arturs.lesinskis@rtu.lv
}

\begin{abstract}
The aim of the paper is to analyse evaporative cooling technologies used in the cooling system and to compare their energy efficiency with traditional cooling systems. Heating and cooling is the most significant energy end-use sector, accounting for about $40 \%$ of total energy demand in the EU. The Member States must achieve cumulative end-use energy savings equivalent to new savings of $0.8 \%$ from final energy consumption in the period and beyond. Therefore, the EU forces buildings and industries to shift to efficient, decarbonized energy systems based on renewable energy sources. The estimated number of cooling systems in Europe will double by 2030. The analysed data set provides results that show how energy efficient the evaporative cooling systems are. The results of this paper show that it is possible to improve the cooling system energy efficiency by using evaporative cooling. The results show that the chiller EER (Energy Efficiency Ratio) can be improved by up to $63 \%$ using the cooling tower. EER is 3.0 of the chiller with a water-cooled condenser - the dry cooler; 3.9 of the chiller with an air-cooled condenser and 4.9 of the chiller with a water-cooled condenser - the cooling tower. Indirect evaporative cooling for air handling units improves EER by $67 \%$ compared when used without indirect evaporative cooling. EER is 4.3 of the air handling unit without indirect evaporative cooling and 7.2 with indirect evaporative cooling. Indirect evaporative cooling is the right way how to increase energy efficiency and minimise carbon footprint by using renewable energy in new and existing air conditioning systems.
\end{abstract}

Keywords: energy efficiency; indirect evaporative cooling.

\section{Introduction}

Energy consumption and efficiency of buildings have been an actual problem for years. Heating and cooling is the most significant energy end-use sector, accounting for about $40 \%$ of total energy demand in the EU. According to the Directive 2010/31/EU on the energy performance of buildings, the Member States shall ensure that by 31 December 2020 all new buildings are nearly zero-energy. Improving the energy performance of HVAC systems is the key to reduce the energy consumption of buildings.

There are different types of HVAC systems, which can maintain the necessary indoor climate requirements. The main task of the HVAC system is to be cost and energy-effective and meet the requirements for indoor climate. The use of evaporative cooling allows to make air conditioning systems energy-effective by using renewable energy and minimise carbon footprint. Chillers and air handling units are the main parts of air conditioning and ventilation system, so the choice is between chillers with water-cooled condenser with dry cooler (WCCH-DC) or cooling tower (WCCH-CT) and air-cooled condenser (ACCH).

Operating data of the chiller and air handling unit with indirect evaporative cooling were collected and analysed. Energy efficiency ratio (EER) of units with indirect evaporative cooling and traditional cooling were compared at equal outdoor air conditions and all other design conditions.

The performance of direct and indirect evaporative cooling systems was studied using existing publications. The use of evaporative cooling for the air-cooled condenser increases the cooling capacity for a chiller, as well increases the EER value, therefore the cooling system efficiency.

It is possible to increase the split air conditioning system EER by $10 \%$, using evaporative precooling for the condenser block. A study showed that the optimal thickness of a surface evaporative cooler is $100 \mathrm{~mm}$. An increase of thickness does not improve EER, because the fan energy usage increases to overcome the pressure drop of the surface evaporative cooler [1]. In comparison to dry cooler systems, an evaporative cooling system that sprays water via nozzles can increase the watercooled chiller EER value by $30 \%$ [2]. Condenser pipes can be coated with a cotton layer, which attracts water and, in this execution, the EER value can be improved by $54.2 \%$ [3]. The spray water in the evaporating cooling system can be cooled before spraying, this improves the overall EER value for the chiller system even taking into account the necessary cooling power to cool the sprayed water [4]. Publication review shows that in some cases the EER value for the chiller can be improved even by 
$113.4 \%$ [5]. Evaporative cooling is one of the most effective ways to increase efficiency of cooling systems and it also can be done in existing systems. According to the Directive EU 2018/844, the renovation of existing buildings into nearly zero-energy buildings should be cost-effective. Upgrading the existing cooling system with evaporating cooling could be a cost-effective strategy.

\section{Materials and methods}

In the present study, two data sets of operating parameters were collected and analysed. The first data set was for the chiller with indirect evaporative cooling and refrigeration system. The second data set was for the air handling unit with indirect evaporative cooling and refrigeration system.

The dry-bulb temperature and relative humidity of the air were measured by a digital temperature and humidity transmitter with an accuracy of $\pm 1{ }^{\circ} \mathrm{C}$ in a range of $-35^{\circ} \mathrm{C}$ to $+70{ }^{\circ} \mathrm{C}$ and $\pm 1.5 \%$ in a range of $0 \%$ to $98 \%$. The pressure of refrigerant was measured by the pressure transmitter with an accuracy of $\pm 0.5 \%$ in a range of 0 bar to 25 bar. All temperature, humidity sensors and pressure transmitters were calibrated.

Power consumption of compressors was calculated using polynomial equation (1), based on a standard [6]. The polynomial equation uses condensing and evaporating temperatures (at dew point) to calculate power consumption of the compressor. In the data set condensing and evaporating pressures were recorded every minute. The evaporating and condensing pressures were converted to dew point temperature for usage in the polynomial equation (1).

$$
P=C_{0}+C_{1} \cdot S+C_{2} \cdot D+C_{3} \cdot S^{2}+C_{4} \cdot S \cdot D+C_{5} \cdot D^{2}+C_{6} \cdot S^{3}+C_{7} \cdot D \cdot S^{2}+C_{8} \cdot S \cdot D^{2}+C_{9} \cdot D^{3},
$$

where $P$-compressor power, $\mathrm{kW}$;

$C_{0}-C_{9}$ - compressor coefficient;

$S$ - evaporating temperature, ${ }^{\circ} \mathrm{C}$;

$D$ - condensing temperature, ${ }^{\circ} \mathrm{C}$.

As seen from equation (1), power consumption depends on evaporating and condensing temperatures, which in turn depend on operating pressures - the higher the pressure, the higher the evaporating and condensing temperatures. An increase of condensing temperature by $1 \mathrm{~K}$ increases energy consumption by $2 \%$.

In order to compare the power consumption of chillers with different types of condensers, equation (2) was used to find the condensing temperature [7]. Evaporating temperature is assumed to be the same in all cases.

$$
t_{k}=t_{\text {cme }}+\Delta \theta_{\text {cond }},
$$

where $t_{k}$ - condensing temperature, ${ }^{\circ} \mathrm{C}$;

$t_{c m e_{c o n d}}-$ temperature of cooling medium entering the condenser, ${ }^{\circ} \mathrm{C}$;

$\Delta \theta_{\text {cond }}-$ condenser split, $\mathrm{K}$.

Condensing temperature depends on the temperature of cooling medium entering the condenser and condenser split. The temperature of the cooling medium for the air-cooled condenser is equal to outdoor air temperature. The temperature of cooling medium for the water-cooled condenser is $5-10 \mathrm{~K}$ above the outdoor air temperature and is assumed $7 \mathrm{~K}$. Condenser split (the difference between the cooling medium temperature entering the condenser and the condensing temperature) is constant for the condenser and is not affected by ambient changes. Condenser split $15 \mathrm{~K}$ is assumed for air-cooled and water-cooled condensers [7]. According to operating data of the analysed chiller (WCCH-CT), the condenser split is $5 \mathrm{~K}$.

Temperature of cooling medium entering the condenser in a chiller with indirect evaporating cooling (respectively, water temperature) is found using equation (3) [7].

$$
t_{w_{\text {cond }}}=t_{\text {outdoor }(\text { wet }- \text { bulb })}+t_{\text {prox }} \text {, }
$$

where $t_{w_{\text {cond }}}-$ water temperature entering the condenser, ${ }^{\circ} \mathrm{C}$;

$t_{\text {outdoor(wet-bulb) }}-$ outdoor air wet-bulb temperature, ${ }^{\circ} \mathrm{C}$;

$t_{\text {prox }}$ - temperature proximity, $\mathrm{K}$. 
Temperature proximity is the difference between the temperature of the water leaving the cooling tower (water entering the condenser) and the outdoor air wet-bulb temperature. It shows how close to outdoor air wet-bulb temperature water could be cooled in a cooling tower. Temperature proximity is constant and for the studied cooling tower it is $5 \mathrm{~K}$.

The first analysed system consists of a chiller with indirect evaporative cooling (cooling tower). Total cooling power is $320 \mathrm{~kW}$, which is ensured by a compressor refrigeration system. Condensation heat is removed in theair-cooled condenser to the exhaust air and in the water condenser, which then transfers the heat to the cooling tower. The chiller is equipped with 4 Copeland ZR-380KCE-TWD compressor model using refrigerant R407C. This compressor is assumed the same for all analysed chiller types.

In Fig. 1 the principal scheme of the chiller with indirect evaporative cooling is shown. The chiller consists of a cooling tower, which uses the indirect evaporating cooling effect, compressors, a water-cooled condenser, air-cooled condenser, free-cooling heat exchanger, water evaporator for process water cooling, and a fan.

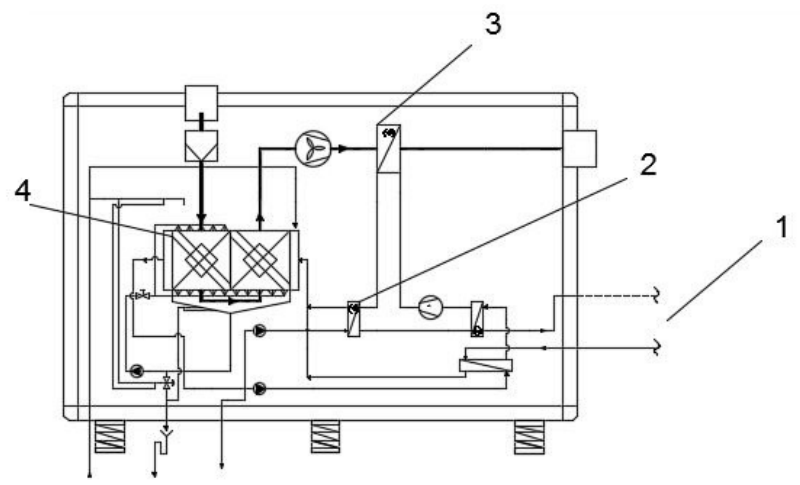

Fig. 1. Principal scheme of chiller with indirect evaporative cooling: 1 - process water; 2 - water-cooled condenser; 3 - air-cooled condenser; 4 - cooling tower

The water temperature in the secondary circuit coming from the cooling tower is higher than the process water temperature coming from the building/process; therefore the free-cooling mode cannot be used, so the total cooling capacity is generated from the compressor refrigeration system. The mentioned operating mode is studied in this paper. The two-stages of the condensation heat output are: 1) the air-cooled condenser to the exhaust air and 2) the water-cooled condenser to the cooling tower. Therefore, the low condensing pressures are achieved to operate with an efficient EER. Secondary circuit water is cooled in the air-water cross-counter flow heat exchanger. In turn, to lower the outdoor air temperature, evaporative cooling is activated.

In Fig. 2 the principal scheme of the chiller with a dry cooler is shown. The chiller consists of a compressor, water-cooled condenser, water evaporator for process water cooling and a dry cooler.

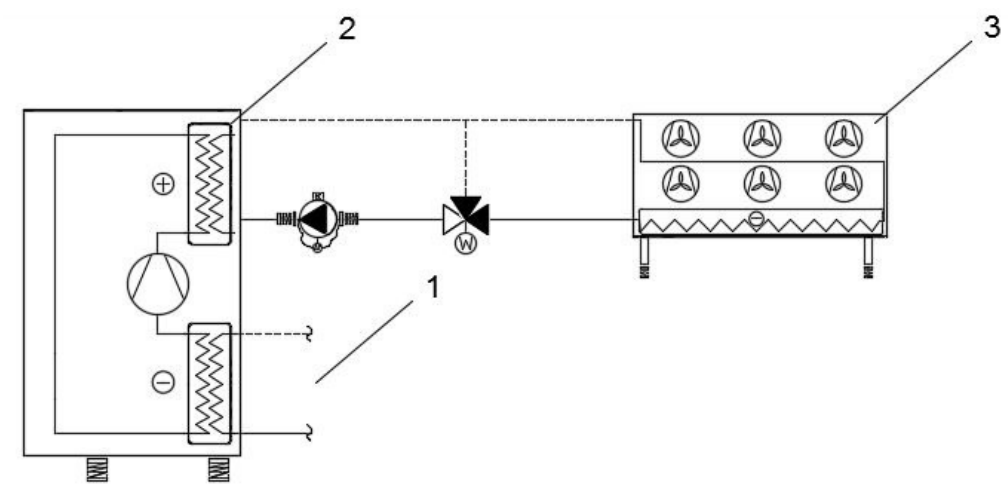

Fig. 2. Principal scheme of chiller with dry cooler: 1 - process water; 2 - water-cooled condenser; 3 - dry cooler

Water condenser in the chiller transfers the condensation heat to the heat medium circuit, which, in turn, circulates the heat medium through the drycooler. Drycooler transfers the heat to the outdoor 
air and consists of a heat exchanger and numbers of fans. Drycooler power is controlled by the rotation speed of modulating fans.

In Fig. 3 the principal scheme of the chiller with an air-cooled condenser is shown. The chiller consists of a compressor, air-cooled condenser, water evaporator for process water cooling and fans.

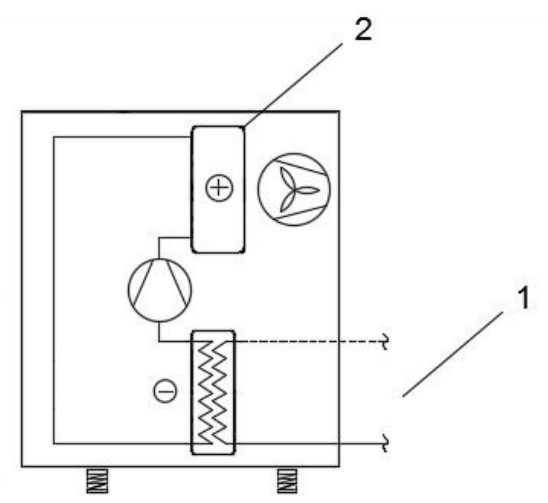

Fig. 3. Principal scheme of chiller with air-cooled condenser: 1 - process water; 2 - air-cooled condenser

Air condenser transfers condensation heat directly to the outdoor air. The air flow going through the condenser is controlled by rotation speed of modulating fans.

In the present study, the performance of indirect evaporating cooling influence on the air handling unit (AHU) refrigeration system cooling capacity and efficiency is also analysed. The impact of indirect evaporative cooling on combined EER is analysed. The cooling system performance with and without indirect evaporative cooling was compared at equal outdoor air and other design parameters.

In Fig. 4 the principal scheme of the air handling unit with indirect evaporative cooling and the refrigeration system is shown. AHU consists of the refrigeration system, where the evaporator cools the supply air and the air condenser transfers condensation heat to the exhaust air.

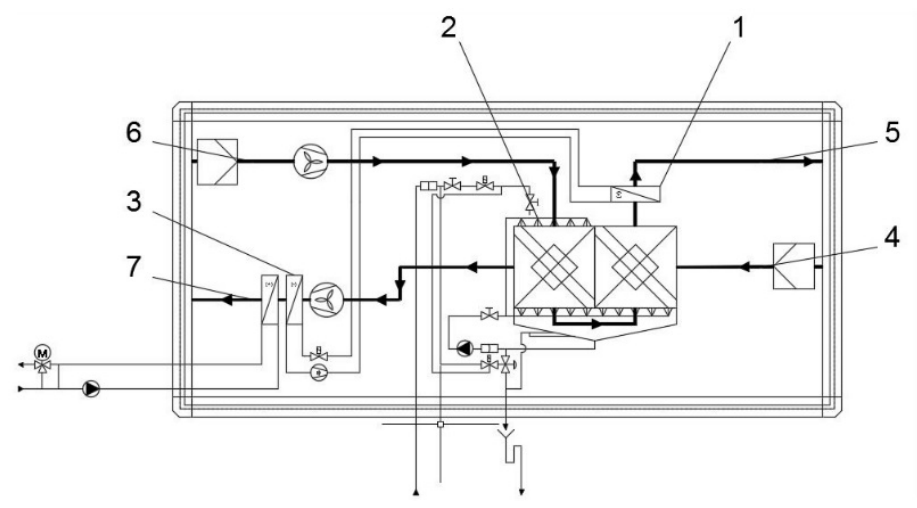

Fig. 4. Principal scheme of air handling unit with indirect evaporative cooling and refrigeration system: 1 - air-cooled condenser; 2 - recuperator with indirect evaporative cooling; 3 - evaporator; 4 - outdoor air; 5 - exhaust air; 6 - extract air; 7 - supply air

The refrigeration system is equipped with Copeland ZPD137KCE-TFD-425 compressor model using refrigerant R410A. AHU unit also is equipped with the indirect evaporating system, where water is sprayed into the recuperator extract air section. Due to evaporation the extract air temperature is decreased and heat exchange in the recuperator between the outdoor air and extract air occurs, thus the outdoor air is cooled. A part of cooling is produced with indirect evaporation and combined EER (refrigeration system with indirect evaporating system) is improved.

To calculate the cooling power of the indirect evaporative cooling system, the supply air temperature after recuperator has to be known and (4) was used to find it.

$$
t_{\text {supply }}=t_{\text {outdoor }}+\eta_{\text {evap }} \cdot\left(t_{\text {outdoor }}-t_{\text {extract(wet-bulb })}\right) \text {, }
$$

where $t_{\text {supply }}-$ supply air temperature after recuperator, ${ }^{\circ} \mathrm{C}$; 
$t_{\text {outdoor }}$ - outdoor air temperature, ${ }^{\circ} \mathrm{C}$;

$t_{\text {extract(wet-bulb) }}$ - extract air wet-bulb temperature, ${ }^{\circ} \mathrm{C}$;

$\eta_{\text {evap }}$ - evaporating cooling efficiency, $\%$.

Equation (5) is used to calculate the cooling capacity of indirect evaporative cooling.

$$
Q_{\text {iec }}=\frac{V_{\text {supply }} \cdot 1.2 \cdot\left(t_{\text {outdoor }}-t_{\text {supply }}\right)}{3600},
$$

where $Q_{i e c}-$ cooling capacity of indirect evaporative cooling, $\mathrm{kW}$;

$V_{\text {supply }}$ - supply air volume, $\mathrm{m}^{3} \cdot \mathrm{h}^{-1}$;

$t_{\text {outdoor }}$ - outdoor air temperature, ${ }^{\circ} \mathrm{C}$;

$t_{\text {supply }}$-supply air temperature after recuperator, ${ }^{\circ} \mathrm{C}$.

Evaporating cooling efficiency is assumed to be the constant at value of 0.8 in all working conditions. In combined EER calculation the circulation pump power of $1 \mathrm{~kW}$ for indirect evaporating cooling is also included.

\section{Results and discussion}

In order to define the most effective EER in different types of condensers, the temperature of cooling medium entering the condenser was analysed and compared. A period of two days was chosen, when the average outdoor air parameters were above $27^{\circ} \mathrm{C} / 60 \%\left(t_{\text {wet-bulb }}=21.1{ }^{\circ} \mathrm{C}\right)$, which are common design parameters for cooling season. The average outdoor air parameters of chosen periodare $28^{\circ} \mathrm{C} / 64 \%\left(t_{\text {wet-bulb }}=22.7^{\circ} \mathrm{C}\right)$. From the analysed dataset, the outdoor air temperature is available and is the same which is entering the air-cooled condenser (ACCH).The water temperature before water condenser for the chiller with a cooling tower (WCCH-CT) was also available from the dataset. Cooling medium entering the condenser with the dry cooler (WCCH-DC) was calculated as $7 \mathrm{~K}$ above the outdoor air temperature. All these temperatures for the chosen period are shown in Fig. 5.

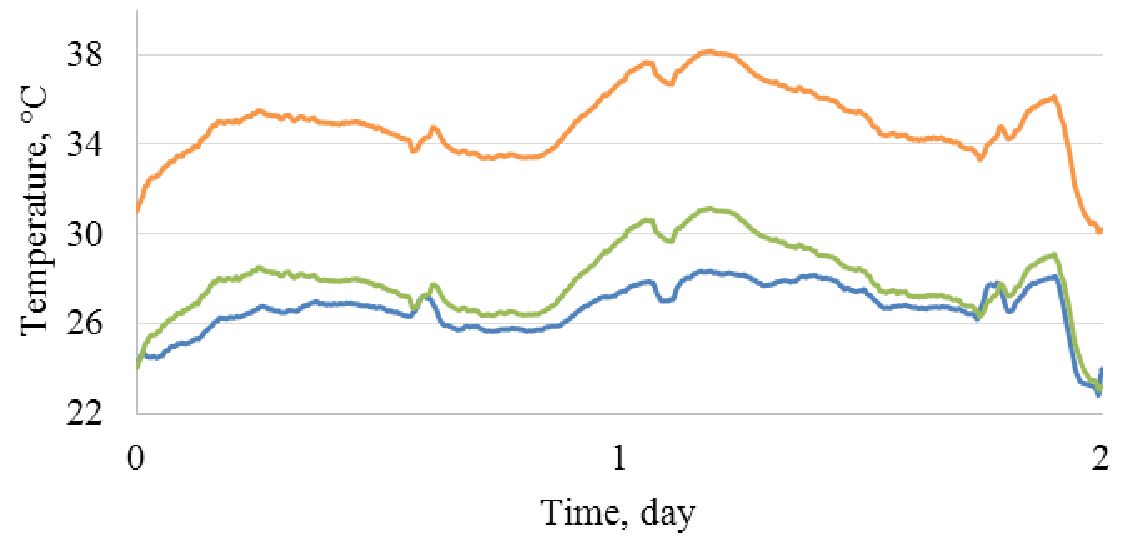

$-\mathrm{WCCH}-\mathrm{CT} \longrightarrow \mathrm{ACCH} \longrightarrow \mathrm{WCCH}-\mathrm{DC}$

Fig. 5. Temperature of cooling medium entering condenser

As seen in the graph (Fig. 5), the lowest temperature of the cooling medium entering the condenser is for WCCH-CT. In the 2-day period, the cooling medium temperature difference between WCCH-CT and WCCH-DC is $8.2 \mathrm{~K}$. This is the effect of the indirect evaporating cooling, which can cool the cooling medium below the outdoor air temperature. The lower the outdoor air wet-bulb temperature, the more efficient indirect evaporative cooling is. As the EER is dependent on the compressor condensing temperature, therefore WCCH-CT will perform more efficiently. Dependence of the system efficiency on the outdoor air temperature and relative humidity should be analysed in further work.

Cooling capacity, power consumption and EER of one compressor with different condenser types are shown in Fig. 6. 


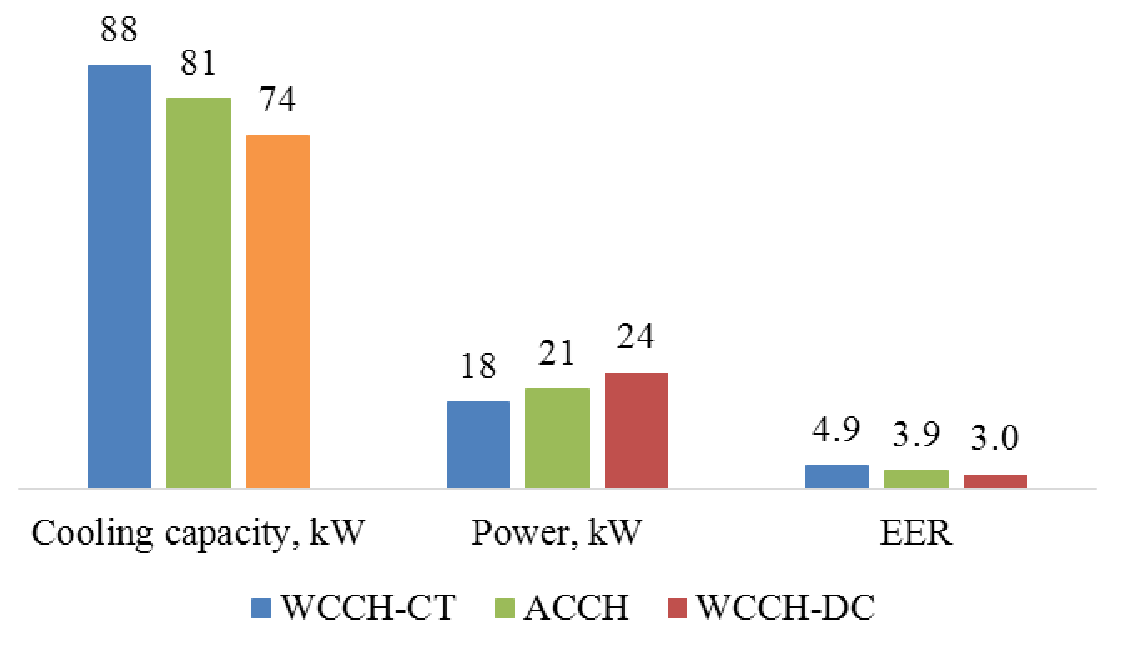

Fig. 6. Operating parameters of one compressor in the same chiller with different condenser types

As a follow-up from Fig. 5,the highest EER of WCCH-CT (4.9)is followed by ACCH (3.9), then WCCH-DC (3.0) (Fig. 6). Indirect evaporative cooling improves EER by $63 \%$ (3.0 and 4.9) compared to WCCH-DC. As seen in Fig. 6, the lowest compressor power consumption $(18 \mathrm{~kW})$ and the highest cooling capacity $(88 \mathrm{~kW})$ has the chiller with indirect evaporative cooling (WCCH-CT) $-33 \%$ less than in the chiller with a dry cooler and $16 \%$ less than in the chiller with an air-cooled condenser.

In Fig. 7 cooling capacity and power consumption of AHU are given in different modes: when the refrigeration system is working with and without indirect evaporative cooling.

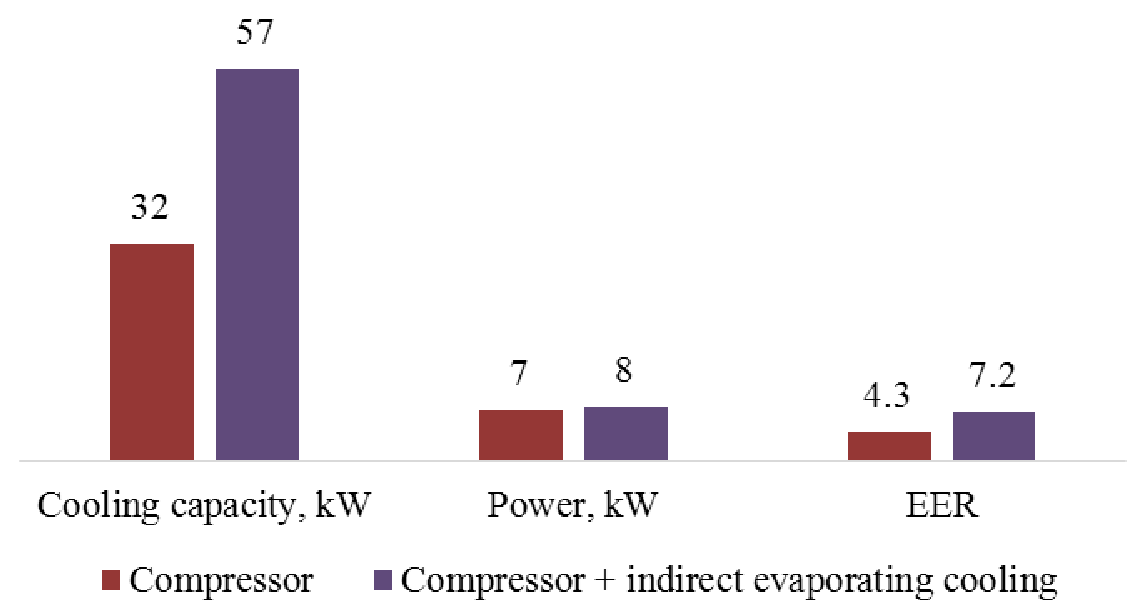

Fig. 7. Cooling capacity, power consumption and EER of AHU with indirect evaporative cooling

According to Fig. 7, indirect evaporative cooling increases the cooling capacity of the analysed AHU in certain conditions by $25 \mathrm{~kW}$ (from $32 \mathrm{~kW}$ to $57 \mathrm{~kW}$ ) and improves EER by $67 \%$.

To evaluate energy efficiency of indirect evaporative cooling, data set of the whole cooling period should be collected and analysed. Moreover, energy consumption of fans and circulating pumps should be considered. The obtained results will allow to calculate the payback time of new or retrofitted air conditioning systems. In Europe, the seasonal efficiency of chillers is often evaluated by the European seasonal energy efficiency ratio (ESEER). The ESEER is calculated by combining full and part load operating Energy Efficiency Ratios (EER), for different seasonal outdoor air temperatures and process water temperatures, and including for appropriate weighting factors. 


\section{Conclusions}

1. The use of indirect evaporative cooling allows to minimise carbon footprint and increase energy efficiency of the air conditioning system by up to $63 \%$ compared to conventional air conditioning systems. EER of WCCH-CT is 4.9, EER of ACCH is 3.9 and EER of WCCH-DC is 3.0.

2. Indirect evaporative cooling significantly increases EER of chillers and air handling units. This should be considered as one of the most effective ways to reduce the energy consumption of buildings.

3. The use of indirect evaporative cooling allows the temperature of the cooling medium entering the condenser to be lower by $8.2 \mathrm{~K}$ than the outdoor air temperature. The lower the outdoor air wetbulb temperature, the more efficient indirect evaporative cooling is.

4. Indirect evaporative cooling increases energy efficiency of the refrigeration system in the air handling unit by $67 \%$ (EER 7.2 and 4.3 accordingly with and without indirect evaporating cooling).

5. ESEER for chillers with different condenser types should be considered.

\section{References}

[1] Martinez P., Ruiz J., Cutillas C.G. etc. Experimental study on energy performance of a split airconditioner by using variable thickness evaporative cooling pads coupled to the condenser. Applied Thermal Engineering Journal, vol. 105, 2016, pp. 1041-1050.

[2] Wei J., Liu J., Xu X. etc. Experimental and computational investigation of the thermal performance of a vertical tube evaporative condenser. Applied Thermal Engineering Journal, vol. $160,2019,114100$.

[3] Kabeel A.E., Bassuoni M.M., Abdelgaied M. Experimental study of a novel integrated system of indirect evaporative cooler with internal baffles and evaporative condenser. Energy Conversion and Management Journal, vol. 138, 2017, pp. 518-525.

[4] Kabeel A.E., El-Samadony Y.A.F., Khiera M.H. Performance evaluation of energy efficient evaporatively air-cooled chiller. Applied Thermal Engineering Journal, vol. 122, 2017, pp. 204213.

[5] Harby K., Gebaly D.R., Koura N.S. etc. Performance improvement of vapor compression cooling systems using evaporative condenser: An overview. Renewable and Sustainable Energy Reviews, vol. 58, 2016, pp. 347-360.

[6] EN 12900:2013 standard "Refrigerant compressors - Rating conditions, tolerances and presentation of manufacturer's performance data".

[7] Котзаогланиан П. Пособие для ремонтника. Справочное руководство по монтажу, эксплуатации, обслуживанию и ремонту современного оборудования холодильных установок и систем кондиционирования (Manual for the technician. Reference guide for the installation, operation, maintenance and repair of modern equipment of refrigeration units and air conditioning systems). Четвёртоеиздание.Москва: Эдем, 2007, 832 с. (In Russian) 